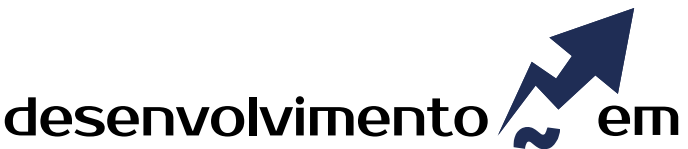 QUESTÃO
}

\section{Gestão de Resíduos Sólidos Integrada às Responsabilidades das Micro e Pequenas Empresas e do Poder Público Municipal}

\author{
http://dx.doi.org/10.21527/2237-6453.2019.49.112-135 \\ Recebido em: 25/10/2018 \\ Aceito em: 4/6/2019 \\ Djair Picchiai, ${ }^{1}$ Fabio Senigalia ${ }^{2}$
}

\begin{abstract}
RESUMO
O objetivo deste trabalho foi evidenciar o conhecimento e a percepção dos administradores de Micro e Pequenas Empresas (MPEs) quanto à gestão dos resíduos sólidos na região do ABC Paulista. A análise considera a aplicabilidade local da Lei $n$ o 12.305/2010 (Política Nacional de Resíduos Sólidos), especificamente dos Planos Municipais de Resíduos Sólidos. Trata-se de um estudo exploratório e qualitativo. Utilizou-se uma amostra de 29 MPEs distribuídas nos setores de comércio, indústria e serviços. $\mathrm{O}$ estudo relata as experiências e práticas desses administradores, compostos em sua maioria por proprietários, mas também com participação de gestores não proprietários. Utilizou-se de coleta documental, a fim de explorar o modelo consorciado da região e o teor dos Planos Municipais, além da técnica da observação direta extensiva, por meio de questionário autoaplicado. Ademais, foram realizadas entrevistas in loco para as categorias de MPE que se apresentaram, para cada setor, em maior quantidade nas sete cidades da região. O questionário foi composto por três partes: (A) por questões fechadas de múltipla escolha; (B) por escala do tipo Likert; (C) por questões abertas. Verificou-se que mais de $60 \%$ dos administradores de MPE não possuem conhecimentos básicos sobre as leis e normas que regem a gestão dos resíduos sólidos e demais compromissos ambientais, por exemplo, a necessidade de possuir licenciamento ambiental quanto ao impacto local ou eventual obrigatoriedade de executar um Plano de Gerenciamento de Resíduos Sólidos (Logística Reversa). Por outro lado, uma parcela significativa de entrevistados mostrou-se disposta quanto às práticas sustentáveis, preocupando-se em utilizar insumos menos agressivos ao meio ambiente em seus processos produtivos e em separar seus resíduos corretamente. Conclui-se que, exceto quanto aos resíduos industriais e de saúde, a interação das MPEs com o poder público local não registrou coesão, observando-se o distanciamento entre as propostas apresentadas pelas prefeituras do ABC nos Planos Municipais e as práticas relatadas pelos administradores.
\end{abstract}

Palavras-chave: Resíduos sólidos. Política Nacional de Resíduos Sólidos. Micro e Pequenas Empresas. Logística reversa. Planos de gestão integrada.

\section{MANAGEMENT OF SOLID WASTE INTEGRATED TO THE RESPONSIBILITIES OF SMALL AND MICRO BUSINESS AND MUNICIPAL PUBLIC POWER}

\section{ABSTRACT}

The objective of this work was to highlight the knowledge and perception of managers of Small and Micro Business (SMB) regarding solid waste management in the $A B C$ Paulista Region. The analysis considers the local applicability of Law N. $12.305 / 2010$ (National Solid Waste Policy), specifically of the Municipal Solid Waste Plans. This is an exploratory and qualitative study. A sample of 29 (twenty-nine) SMB distributed in the commerce, industry and services sectors was used. The study reports the experiences and practices of these managers, composed mostly by owners, but also with the participation of non-proprietary managers. A documentary collection was used in order to explore the intercropping model of the region and the content of the Municipal Plans, in addition to the extensive direct observation technique, through a self-administered questionnaire. In addition, interviews were conducted on the spot for the categories of SMB that presented themselves, for each sector, in greater quantity in the seven cities of the region. The questionnaire was composed of three parts: (A) for multiple choice closed questions; (B) for Likert type scale; (C) for open questions. It was verified that more than $60 \%$ of SMB managers do not have basic knowledge about the laws and regulations governing solid waste management and other environmental commitments, for example, the need to have environmental licensing regarding the local impact or possible to carry out a Solid Waste Management Plan (Reverse Logistics). On the other hand, a significant number of respondents showed a willingness on sustainable practices, worrying about using less aggressive inputs to the environment in their productive processes and to separate their waste correctly. It concluded that, except for industrial and health waste, the interaction of MSE with the local Government did not register cohesion, highlighting the distance between the proposals presented by the municipal governments of $A B C$ in the Municipal Plans and the practices reported by the administrators.

Keywords: Solid waste. National Policy on Solid Waste. Small and micro business. Reverse logistic. Integrated management plans.

\footnotetext{
${ }^{1}$ Doutor em Administração pela Fundação Getulio Vargas de São Paulo (FGV-SP). Professor do Centro Universitário Campo Limpo Paulista (Faccamp) e da Fundação Getulio Vargas de São Paulo (FGV-SP). djair.picchiai@fgv.br

${ }^{2}$ Mestre em Administração pelo Centro Universitário Campo Limpo Paulista (Faccamp). Servidor público da Universidade Federal do ABC. senegalia@gmail.com
} 
A geração de resíduos sólidos possui uma forte relação, em proporção e diversidade, com o aumento da sociedade de consumo e o processo desordenado de ocupação dos centros urbanos. Fatores como a modificação e aumento dos hábitos de consumo, a concentração populacional nos grandes centros urbanos, além do forte incremento de produção e vendas de produtos, constituem influenciadores na geração de resíduos sólidos (LEMOS, 2014). O gerenciamento inadequado dos resíduos sólidos, no entanto, gera problemas para toda a sociedade e resulta, ao mesmo tempo, em riscos indesejáveis à saúde pública e à degradação do meio ambiente. A preservação ambiental e a saúde pública devem ser priorizadas nas ações de gestão dos resíduos sólidos, devendo-se considerar ainda os aspectos sociais, estéticos, econômicos e administrativos locais (BROLLO; SILVA, 2001).

Para a sociedade brasileira, especialmente nas áreas urbanas, o desafio da sustentabilidade passou a ocupar um papel de destaque com a promulgação da Lei no 12.305/2010, a Política Nacional de Resíduos Sólidos (PNRS). O marco regulatório foi aprovado após discussões entre governo, instituições privadas, Organizações Não Governamentais e sociedade civil, estabelecendo a distinção entre resíduo (lixo aproveitável) e rejeito (não aproveitável), além de criar a classificação dos tipos de detritos: doméstico, industrial, eletrônico, construção civil, saúde, entre outros (BRASIL, 2014; RAUBER, 2011). O objetivo desta lei é viabilizar a redução, reuso ou destinação final ambientalmente adequada dos resíduos sólidos. Estes resíduos não mais podem ser considerados simplesmente como "lixo", uma vez que possuem valor econômico e social. Medidas relacionadas com a reutilização e reciclagem, bem como seu retorno como matéria-prima para o setor produtivo compõem o escopo da PNRS.

Além disso, a PNRS ainda prevê a atuação integrada dos geradores (fabricantes, importadores, distribuidores, comerciantes e consumidores) e do poder público (titulares dos serviços públicos de limpeza urbana e de manejo dos resíduos sólidos), os quais possuem atribuições específicas decorrentes da responsabilidade compartilhada pelo ciclo de vida dos produtos. O poder público tem a responsabilidade pela organização e prestação direta ou indireta de ações que assegurarem a observância da PNRS, tais como: coleta seletiva, recuperação e reciclagem, tratamento e destinação final dos resíduos sólidos. Para isso, os Planos de Gestão Integrada de Resíduos Sólidos surgem como instrumentos que preveem essas soluções de forma integrada (BRASIL, 2010).

Na esfera municipal, embora o Plano de Gestão Integrada de Resíduos Sólidos não seja uma obrigatoriedade da PNRS, este se tornará um requisito para que os municípios obtenham acesso a recursos da União destinados à gestão e ao gerenciamento de resíduos sólidos. Os planos devem conter metas que visem a reduzir a quantidade de rejeitos encaminhados para disposição final ambientalmente adequada, além de um conjunto de ações voltadas para a busca de soluções para os resíduos sólidos gerados no município, considerando as peculiaridades locais (PEREIRA, 2011). Por outro lado, compete aos geradores do setor empresarial a instituição de um sistema de logística reversa, definida na PNRS como um instrumento de desenvolvimento, tanto econômico quanto social, caracterizado por um conjunto de ações, procedimentos e meios que visam à coleta e restituição dos resíduos sólidos ao setor produtivo para reaproveitamento ou outra destinação final ambientalmente adequada (BRASIL, 2010). 
Há de se considerar as dificuldades para instalação de um sistema de logística reversa. As organizações, muitas vezes, consideram que as barreiras enfrentadas ao desenvolver estas práticas são maiores do que as vantagens (GONZÁLES-TORRE et al., 2010; ROGERS; TIBBEN-LEMBKE, 2002). Montoya et al. (2015) afirmam que entraves no campo financeiro e a falta de conscientização ambiental são alguns dos exemplos que as organizações enfrentam na efetivação de programas de logística reversa. Problemas esses sentidos especialmente pelas Micro e Pequenas Empresas (MPEs). Enquanto as grandes empresas possuem capital suficiente para contratar escritórios especializados em gestão ambiental, as MPEs apresentam dificuldades para o gerenciamento de seus resíduos sólidos (ZAMBRANO; MARTINS, 2007).

Tachizawa e Andrade (2008) destacam que quanto antes os empresários adotarem a sustentabilidade como seu principal desafio e oportunidade competitiva, maiores serão as chances de sobrevivência de seu negócio. Houve um crescimento quanto à discussão da temática ambiental nas empresas, motivado pela necessidade de ordens legais e também pela percepção da responsabilidade socioambiental dos gestores. Esse nível de consciência, contudo, pode variar entre diferentes sociedades e entre as distintas realidades das organizações, a depender das atividades desenvolvidas, objetivos, cultura e do seu respectivo tamanho (FARIAS; TEIXEIRA, 2002).

As MPEs constituem um cenário promissor para estudos na temática ambiental, pois compõem um panorama marcado por restrições financeiras em investimentos na área ambiental e dificuldades na disponibilidade de tempo por parte do gestor em cuidar dessas ações, considerando que, muitas vezes, este é o único responsável por todas as etapas do negócio (FARIAS; TEIXEIRA, 2002). Esses negócios totalizam cerca de $99 \%$ das empresas privadas no Brasil, aproximadamente 6,6 milhões de estabelecimentos. São responsáveis por $27 \%$ de participação no Produto Interno Bruto (PIB) nacional e respondem por $52 \%$ de empregos do setor privado, cerca de 17,1 milhões de postos de trabalho (SEBRAE, 2015).

Considerando que uma parcela das MPEs transfere seus resíduos ao serviço público de limpeza, percebe-se a dimensão do problema da inadequada destinação dos resíduos (SINIR, 2011). Esses resíduos, provenientes do consumo de bens e serviços, desencadeiam graves problemas para o poder público local, representando desperdícios consideráveis de recursos naturais (JESUS; BARBIERI, 2013).

Nesta linha de discussão, buscou-se analisar o conhecimento e a percepção de administradores de MPE quanto à gestão dos resíduos sólidos, assim como as ações internas e as inter-relações com o poder público local, levando em consideração as diretrizes dos Planos Municipais de Gestão Integrada de Resíduos Sólidos. A amostra compreende MPEs da região do $A B C$ Paulista, uma área formada por sete municípios, localizada no Estado de São Paulo, com uma população de 2,6 milhões de habitantes, distribuída em território de $828 \mathrm{~km}^{2}$. A região compreende importantes complexos industriais, elevado grau de urbanização e ainda amplos espaços e reservas naturais destinados à preservação ambiental (AGÊNCIA ABC, 2016). 


\section{MODELO TEÓRICO}

\section{A Importância das MPE e a Responsabilidade Socioambiental}

O conceito de microempresa foi criado pela Lei no 7.256, de 27 de novembro de 1984. A legislação sofreu diversas alterações até a instituição do Estatuto Nacional da Microempresa e da Empresa de Pequeno Porte em 2006, com o advento da Lei Complementar no 123, de 14 de dezembro de 2006 (BRASIL, 2006). A Constituição Federal de 1988 prevê em seu artigo 179 que as microempresas e as empresas de pequeno porte possuirão "tratamento jurídico diferenciado, visando incentivá-las pela simplificação de suas obrigações administrativas, tributárias, previdenciárias e creditícias, ou pela eliminação ou redução destas por meio de lei" (BRASIL, 2017). As regulamentações fomentaram um crescimento no número de MPEs no país e, segundo o IBGE, esse aumento tornou-se um dos fatores responsáveis pelo desenvolvimento econômico nacional (CUNHA; SOARES, 2010).

As MPEs protagonizam as cadeias de fornecimento no mundo, atuando como fornecedoras, distribuidoras ou subcontratadas (MONTOYA et al., 2015). Especialmente na economia brasileira, as MPEs destacam-se como as principais indutoras de empregos, além de contribuírem para o resultado do PIB (RALIO; DONADONE, 2015). Dados da Relação Anual de Informações Sociais (Rais) registram 6,6 milhões de empresas de micro e pequeno porte no Brasil, responsáveis pela criação de 17,1 milhões de empregos formais privados não agrícolas (SEBRAE ORG., 2015).

Diante da importância das MPEs para o país, reforça-se o papel do gestor na manutenção da sustentabilidade de seu negócio. Os empresários precisam satisfazer não somente às questões legais, mas também atender aos interesses de diferentes agentes: acionistas, funcionários, clientes, fornecedores, comunidade local, entre outros. A depender do segmento praticado na economia, serão requeridas "estratégias empresariais por vezes conflitantes à primeira vista, tais como lucratividade e responsabilidade ambiental" (LEITE, 2012, p. 183). A responsabilidade socioambiental é o retorno das empresas ao novo cliente: "o 'consumidor verde' e ecologicamente correto" (TACHIZAWA; ANDRADE, 2008, p. 1). As empresas que adotam práticas ambientais tornam-se sinônimo de bons negócios, ensejando uma forma duradoura e lucrativa ao empreender. Quanto antes os empresários adotarem a sustentabilidade como seu principal desafio e oportunidade competitiva, maior será a chance de sobrevivência (TACHIZAWA; ANDRADE, 2008).

Percebe-se, todavia, que o foco dos fabricantes ainda está no "desempenho nos processos de fabricação, venda e distribuição, desconsiderando a destinação dada pelos clientes aos produtos ao final de sua vida útil" (DEMAJOROVIC; CAIRES; GONÇALVES, 2014, p. 517). Esse paradigma demonstra que para estes fabricantes os custos envolvidos com práticas ambientais são maiores do que os benefícios econômicos que podem ser obtidos (DEMAJOROVIC; CAIRES; GONÇALVES, 2014). Consumidores cada vez mais preocupados com seus hábitos de consumo, no entanto, usam do seu poder de compra para censurar empresas irresponsáveis e alavancar as que se comprome- 
tem com ações sociais e ambientais. Nesse caso, alguns gestores percebem oportunidades a serem exploradas junto aos consumidores e parceiros que estão à procura de fornecedores que os acompanhem no desempenho socioambiental (GIOVANNINI; KRUGLIANSKAS, 2008).

\section{Logística Reversa}

Desde a Segunda Guerra Mundial as referências à logística tornaram-se presentes nas dinâmicas empresariais, principalmente por envolver questões decisivas. A gestão de transportes e estoques, presentes nesta discussão, converteram-se em atividades fundamentais para o sucesso de qualquer negócio (DEMAJOROVIC; MIGLIANO, 2013). Os canais de distribuição reversos, contudo, destacaram-se na literatura após 30 anos, tratada à época como uma área em ascensão dentro da logística tradicional (GONÇALVES-DIAS; TEODÓSIO, 2006; ZUCATTO; WELLE; SILVA, 2013). Artigos acadêmicos sobre logística verde ou logística reversa começaram a ser encontrados a partir da década de 70 do século 20 (DEMAJOROVIC et al., 2011; RUBIO; CHAMORRO; MIRANDA, 2008).

A década de 80 é marcada pela ênfase estratégica às operações logísticas, quando estas passaram a representar um elemento diferenciador na busca por vantagens competitivas pelas empresas. Incluíram-se novas discussões nos projetos de sistemas logísticos, como a responsabilidade socioambiental (CHAVES; BATALHA, 2006; FIGUEIRÓ et al., 2014). Naquela época, as abordagens sobre logística reversa limitavam-se a gerir o movimento contrário ao fluxo direto da produção (CHAVES; BATALHA, 2006; FIGUEIRÓ et al., 2014). Tal abordagem, no entanto, mesmo que limitada, provocou um aumento dos estudos sobre os fluxos diretos e de retornos dos itens rejeitados, exigindo considerações adicionais e específicas (DEMAJOROVIC; MIGLIANO, 2013). Rogers e Tibben-Lembke (1998) e Gungor e Gupta (1998) observam que naquela época o conceito de logística verde ainda era restrito a um modismo ou mero apelo mercadológico, pois simplesmente tratavam os resíduos do berço (produção) à cova (descarte).

A partir da década de 90 elucidaram-se os conceitos de desenvolvimento sustentável, esclarecendo a relação: objetivo econômico versus meio ambiente versus descarte versus recuperação de bens (TADEU et al., 2012). Foi neste período que as empresas passaram a enxergar a logística reversa como uma importante fonte de redução de perdas (CHAVES; BATALHA, 2006; GARDIN; FIGUEIRÓ; NASCIMENTO, 2010).

As definições dadas à logística reversa continuaram a evoluir no decorrer dos anos. Trata-se de uma abordagem em plena exploração, apresentando um interesse crescente na perspectiva dos empresários e acadêmicos, revelando conceitos, classificações, critérios e operacionalizações em desenvolvimento (LEITE, 2009). Daher, Silva e Fonseca (2006) destacam que logística reversa é um termo genérico, e em sentido amplo está presente em todas as operações relacionadas com a reutilização de produtos e materiais. Corrêa e Silva (2013) indicam que a cadeia reversa diferencia-se do modelo tradicional por apresentar sentido oposto na cadeia de suprimentos, como pode ser observado na Figura 1. 
Figura 1 - Processo logístico tradicional e reverso

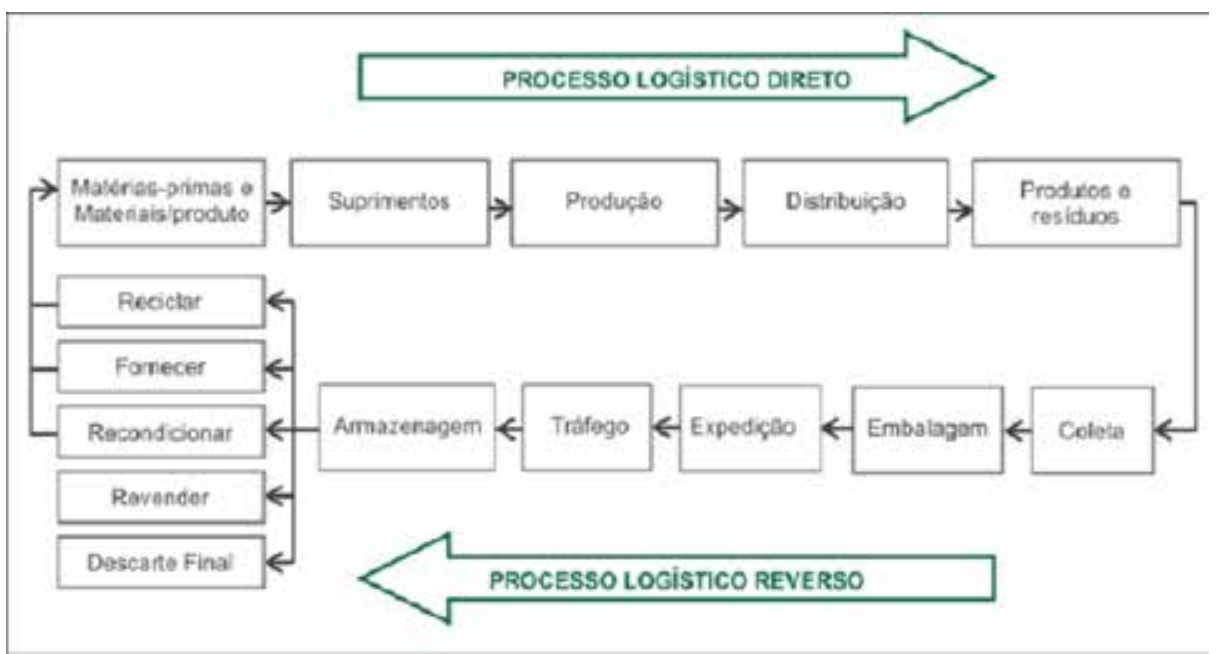

Fonte: CORRÊA; SILVA, 2013.

O Council of Supply Chain Management Professionals (CSCMP, 2017), entidade internacional composta por profissionais da área de logística com sede nos Estados Unidos, apresenta uma das definições mais utilizadas na literatura: "Um segmento especializado de logística com foco no movimento e gerenciamento de produtos e recursos pós-venda e após a entrega ao cliente. Inclui os retornos dos produtos para reparação e/ou crédito" (CSCMP, 2017, tradução nossa). Gonçalves, Tanaka e Amedomar (2013) resumem que a logística reversa depende da gestão adequada dos canais de distribuição, do ponto de consumo até o ponto de origem, tendo como meta a recuperação do valor ou tratamento apropriado do lixo gerado.

Araújo e Juras (2011), contudo, destacam que raramente a distribuição direta se encaixa nas necessidades da logística reversa. Enquanto a logística tradicional é projetada para ofertar grandes volumes de um mesmo produto, na logística reversa o mix de produtos pode variar consideravelmente, apresentando volumes muito baixos em alguns casos. Diante deste cenário, a economia de escala no transporte dificilmente é alcançada. Destaca-se também a dificuldade em proteger os produtos recolhidos que percorrem os fluxos reversos, ocasionando o risco de danificá-los.

A logística reversa não serve necessariamente para aprimorar a produtividade logística. No entanto, o movimento reverso é justificado sobre uma base social e deve ser acomodado no planejamento do sistema logístico. O ponto importante é que a estratégia logística não poderá ser formulada sem uma consideração cuidadosa dos requerimentos da logística reversa (BOWERSOX et al., 1986 apud DAHER; SILVA; FONSECA, 2006, p. 16).

A abordagem de logística reversa tem se desenvolvido sob uma crescente conscientização ecológica, haja vista os impactos que os resíduos podem causar no meio ambiente (GIACOBO; ESTRADA; CERETTA, 2003). Há vários benefícios que poderiam ser atingidos pela logística reversa, como a eficiência no uso dos recursos e a proteção do ambiente (ABDULRAHMAN; GUNASEKARAN; SUBRAMANIAN, 2014). A recuperação dos resíduos sob as formas de reuso, reciclagem e revalorização energética contribui para o aumento da vida útil dos aterros sanitários, além de reduzir a coleta de Resíduos Sólidos 
Urbanos (RSU), por exemplo. Dessa forma, atendem-se às necessidades de produção de bens e serviços demandados pela sociedade com vistas ao aumento da sustentabilidade (JESUS; BARBIERI, 2013).

\section{A Política Nacional de Resíduos Sólidos}

A Política Nacional de Resíduos Sólidos (PNRS), lei no 12.305/2010, surgiu para consolidar normas dispersas no ordenamento jurídico. O documento teve sua trajetória legislativa iniciada em 1989 pelo Projeto de Lei do Senado no 354, o qual dispunha sobre o condicionamento, coleta, tratamento, transporte e a destinação final dos resíduos de serviços de saúde (BRASIL, 2014). Em março de 2010 a Subemenda Substitutiva de Plenário alterou significativamente as disposições originais do projeto, instituindo uma norma abrangente e geral sobre a Política Nacional de Resíduos Sólidos. O projeto de lei retornou em março de 2010 para o Senado Federal, e aprovado, foi enviado para sanção presidencial em julho do mesmo ano (BRASIL, 2014).

A Lei no 12.305/2010 reúne princípios, objetivos, instrumentos, diretrizes, metas e ações a serem adotados pela União isoladamente ou em parceria com Estados, Distrito Federal, municípios e particulares. Visa-se à gestão integrada e ao gerenciamento ambientalmente adequado dos resíduos sólidos. Destaca-se que a PNRS diferencia o gerenciamento de resíduos sólidos da gestão integrada de resíduos sólidos na medida em que o gerenciamento de resíduos sólidos é voltado para um aspecto particular das ações a serem tomadas pelos geradores de resíduos, aplicada principalmente ao setor privado. A gestão integrada de resíduos sólidos apresenta um caráter mais amplo dentro de uma perspectiva macro de ações voltadas à busca de soluções para os resíduos sólidos, considerando as facetas políticas, econômicas, ambientais, culturais e sociais, aplicada pelo setor público dentro de suas políticas públicas (LIMA, 2011). O gerenciamento de resíduos sólidos deverá observar as previsões e determinações contidas nos instrumentos específicos, seja no plano federal, estadual ou municipal de gestão integrada de resíduos sólidos (artigos 16 e 19), ou no plano de gerenciamento de resíduos sólidos (artigo 2) (BRASIL, 2017).

Maia et al. (2014) recordam que a PNRS deverá ser aplicada de forma integrada às normas ambientais brasileiras, complementando-se pela Lei no 6.938/1981 (Política Nacional de Meio Ambiente), Lei no 11.445/2007 (Política Nacional de Saneamento Básico), Lei no 9.795/1999 (Política Nacional de Educação Ambiental) e Lei no 10.257/2001 (Estatuto da Cidade). A partir destes instrumentos legais, o poder público deverá articular a promoção da gestão dos resíduos sólidos gerados em seu território.

Dessa forma, a PNRS fortaleceu o debate sobre logística reversa e instituição das respectivas iniciativas no Brasil (DEMAJOROVIC; MIGLIANO, 2013). A lei estabeleceu uma motivação para o crescimento das iniciativas em logística reversa no país, revelando-se um instrumento moderno e ousado de política pública, o qual definiu instrumentos de comando e controle, agregando benefícios econômicos ao incorporar princípios e o conceito de responsabilidade compartilhada sobre o ciclo de vida dos produtos e respectivas embalagens (OLIVEIRA et al., 2015). 


\section{Planos Municipais de Gestão Integrada}

O poder público municipal deverá criar o Plano Municipal de Gestão Integrada de Resíduos Sólidos como condição para obter acesso a recursos da União, conforme previsto nos artigos 18 e 19 da Lei no 12.305/2010. Pereira (2011) explica que os municípios são responsáveis pelo maior número de deveres, pois estes são detentores de competência constitucional para realização de serviços locais. $O$ artigo 19 da Lei no 12.305/2010 determina o conteúdo mínimo que o Plano Municipal de Gestão Integrada de Resíduos Sólidos deverá conter. Segundo Tomaz (2012), o plano é composto por cinco grupos de assuntos principais:

- diagnóstico e identificação;

- serviço público de limpeza urbana e manejo de resíduos sólidos;

- programas e ações;

- plano de gerenciamento de resíduos;

- logística reversa.

O primeiro grupo, quanto ao diagnóstico e identificação, prevê que é dever dos municípios contemplar em seus planos o diagnóstico da situação dos resíduos sólidos gerados em seus respectivos territórios, identificar áreas favoráveis para a disposição final de rejeitos, possibilidades de adoção de soluções consorciadas com outros entes e a identificação dos passivos ambientais relacionados com resíduos sólidos e áreas contaminadas com respectivas medidas saneadoras (BRASIL, 2017; TOMAZ, 2012).

No segundo grupo são abordados assuntos referentes aos serviços públicos de limpeza urbana e manejo de resíduos sólidos. Os planos municipais devem contemplar procedimentos operacionais e especificações mínimas a serem adotados em tais serviços, indicadores de desempenho operacional e ambiental, o sistema de cálculo dos custos da prestação dos serviços e, ainda, as formas de cobrança (BRASIL, 2017; TOMAZ, 2012).

Os programas e ações, objetos do terceiro grupo, são voltados para a capacitação técnica quanto à instalação e operacionalização do próprio plano municipal. Prevê programas e ações de educação ambiental voltados para a participação de cooperativas e outras formas de associação de catadores de materiais reutilizáveis e recicláveis. Deve também atender aos mecanismos para a criação de fontes de negócios, emprego e renda por meio da valorização dos resíduos sólidos, ações preventivas e corretivas a serem praticadas, além do programa de monitoramento (BRASIL, 2017; TOMAZ, 2012).

O quarto grupo determina os atores sujeitos à elaboração do plano de gerenciamento de resíduos sólidos, quais sejam: geradores de resíduos perigosos, construção civil, agrossilvopastoris, saneamento básico, serviços de saúde, industriais e de mineração, ou que pelo volume ou características não podem ser considerados domiciliares (TOMAZ, 2012).

No último grupo a PNRS identifica os geradores submetidos ao sistema de logística reversa, determinando as formas e limites da participação do poder público municipal nesse sistema e os meios a serem utilizados para controle e fiscalização dos sistemas de logística reversa (BRASIL, 2017). 
Ademais, compete aos planos municipais a identificação de áreas favoráveis à disposição final dos resíduos sólidos. Observado o Plano Diretor e a Lei de Zoneamento, os municípios devem contemplar em seus Planos os locais viáveis para instalação de aterros e infraestruturas operacionais dos agentes integrantes do serviço público de limpeza urbana e manejo (TOMAZ, 2012). Além disso, a legislação ainda prevê a possibilidade de um modelo simplificado de plano municipal para localidades com menos de 20.000 habitantes, exceto aqueles municípios integrantes de áreas de especial interesse turístico, área de influência de empreendimentos ou atividades de significativo impacto ambiental - regional ou nacional - ou cujo território abranja, total ou parcialmente, Unidades de Conservação (BRASIL, 2017).

\section{MÉTODO}

Tratou-se de um estudo exploratório, do tipo qualitativo, sob a abordagem não probabilística e tipo de amostragem por acessibilidade ou conveniência. Tal amostra abrangeu MPEs localizadas na região do ABC Paulista. Essa região é conhecida por ser percursora da indústria automobilística no Brasil, processo iniciado em meados da década de 50. Os sete municípios da região do ABC Paulista (Santo André, São Bernardo do Campo, São Caetano do Sul, Diadema, Mauá, Ribeirão Pires e Rio Grande da Serra) integram uma das 15 mesorregiões do Estado de São Paulo (SEADE, 2010). A região do ABC Paulista possui uma população de aproximadamente 2,6 milhões de habitantes, distribuídos em um território de $828 \mathrm{~km}^{2}$. Além disso, a região contempla diversos complexos industriais, alto grau de urbanização e importantes reservas naturais destinadas à preservação ambiental, cuja produção de água é parte importante do sistema de abastecimento metropolitano (AGÊNCIA ABC, 2016). Destaca-se que, somados os sete municípios, a região apresenta o quarto maior PIB do Brasil, com receita de $\mathrm{R} \$ 70,3$ bilhões, equivalentes a 2,3\% do índice nacional ( $A G E \hat{N} N C I A A B C, 2016)$.

Foram adotadas diferentes técnicas de coleta de dados, especificamente a aplicação da observação direta extensiva, bem como da coleta documental de arquivos públicos e fontes estatísticas (dados primários ou secundários). A observação direta extensiva segue a teoria de Marconi e Lakatos (2010), a qual se caracteriza pelo uso de instrumentos como questionários, formulários, medidas de opinião e atitude, e de técnicas mercadológicas. $\mathrm{O}$ instrumento utilizado foi um questionário autoaplicado, contendo perguntas fechadas e abertas. Os respondentes foram contatados pessoalmente ou por correio eletrônico (e-mail) e convidados a acessar a pesquisa pelo endereço eletrônico "http://www.meusresiduos.com.br". Os entrevistados puderam optar pelo preenchimento do instrumento na forma impressa, o qual seria encaminhado pessoalmente ou por e-mail.

O questionário foi dividido em três partes denominadas: ' $A$ ', ' $B$ ' e 'C', assim discriminadas: (i) PARTE A: Composta por 8 perguntas fechadas; (ii) PARTE B: Composta por 14 questões fechadas, utilizando-se uma escala do tipo Likert de cinco pontos; (iii) PARTE C: Composta por 3 questões abertas, nas quais os participantes responderam livremente sobre o tema abordado. A parte ' $A$ ' investigou o conhecimento dos respondentes sobre a gestão e gerenciamento de resíduos sólidos, considerando as respectivas inter-relações com o poder público local, enquanto as partes ' $B$ ' e 'C' registraram a percepção 
dos respondentes quanto à responsabilidade compartilhada na gestão e gerenciamento de resíduos sólidos, exemplificada por indicadores propostos para os Planos Municipais de Gestão Integrada de Resíduos Sólidos.

Houve uma preocupação prévia quanto a não hegemonia no perfil dos respondentes. Diante disso, selecionou-se ao menos uma MPE a ser entrevistada para cada principal classe e/ou subclasse segundo a Classificação Nacional de Atividade Econômica (Cnae), dos três setores de atividades que possuem maior incidência no ABC Paulista, conforme dados do Escritório Regional no $A B C$ do Serviço Brasileiro de Apoio às Micro e Pequenas Empresas (Sebrae). No total, dez empresas foram entrevistadas, seguindo o roteiro do questionário autoaplicado.

$\mathrm{Na}$ etapa seguinte, com a pesquisa documental, pretendeu-se verificar quais municípios realizaram seus Planos de Gestão Integrada de Resíduos Sólidos. Nesse caso, coletaram-se informações referentes às metas de redução e formas propostas para destinação final ambientalmente adequada dos resíduos e rejeitos. Adicionalmente, seguindo a teoria de Tachizawa (2017), foi feito um diagnóstico quanto ao quadro sustentável das MPEs, seguindo informações presentes em seus respectivos sites institucionais. Exploraram-se os certificados socioambientais apresentados pelas MPEs e, ainda, a existência do comprometimento da alta administração com a sustentabilidade empresarial na missão declarada pelas organizações.

\section{ANÁLISES}

\section{Caracterização da Amostra}

Participaram deste estudo 29 micro e pequenos empresários/gestores de empresas dos setores de serviços (45\%), comércio (41\%) e da indústria (14\%). Duas empresas não completaram o preenchimento do formulário eletrônico, sendo descartadas da presente análise. Outras duas empresas declararam não estar localizadas geograficamente na região do $A B C$ Paulista, totalizando o descarte de 4 empresas. Ademais, outras 15 empresas não retornaram os e-mails e tentativas de contato por telefone. Apesar da dificuldade em atingir o número esperado de respondentes, houve aceitação pela maior parte dos empresários e gestores contatados.

A maioria das MPEs pesquisadas iniciou seus negócios após a década de 2000, com média de 13,34 anos de existência. Além disso, constatou-se a predominância de respondentes do gênero masculino (61,54\%), com idade entre 23 e 60 anos, enquanto $38,46 \%$ eram mulheres, com idade entre 33 e 59 anos. A média da faixa etária, para ambos os gêneros, foi de 42,57 anos. Quanto ao nível de escolaridade, $73,08 \%$ declararam ter nível superior completo e deste montante $15,38 \%$ possuíam alguma especialização/MBA. Os demais $(7,69 \%)$ declararam ter curso superior incompleto ou Ensino Médio completo (19,23\%). Não houve registro de nível de escolaridade inferior ao Ensino Médio.

Em relação à posição profissional dos respondentes em seus respectivos negócios, $83 \%$ apresentaram-se como proprietários ou sócio/proprietários. O restante (17\%) correspondia aos cargos de diretores, administradores ou assistentes administrativos, conforme terminologias declaradas pelos respondentes. Esses dados contribuíram na 
análise posterior das percepções encontradas, e suas possíveis diferenças quanto à forma de interpretarem a gestão e gerenciamento dos resíduos sólidos. No que se refere à localização, a maior parcela de empresas estava assim distribuída: 31\% em Santo André, $28 \%$ em São Bernardo do Campo e 17\% em São Caetano do Sul.

Quanto ao diagnóstico socioambiental proposto por Tachizawa (2017), a maior parcela de empresas respondentes não possuía missão declarada em seus sites. Ademais, alguns prestadores de serviços sequer possuíam páginas próprias, inviabilizando o acesso à sua missão. Os comércios varejistas, de forma geral, também não apresentavam características socioambientais, ao menos quanto à análise da missão. $\mathrm{Na}$ mesma linha da pesquisa, a maioria das empresas respondentes (81\%) não possuía quaisquer certificações ambientais e parte delas (12\%) afirmou (institucionalmente) seguir as leis de resíduos sólidos. Destaca-se que duas empresas praticavam exportação simplificada.

MPEs do setor industrial afirmaram possuir compromissos declarados em sua missão, especialmente quanto ao item "compromisso com a sustentabilidade empresarial". Uma das MPEs apresentava o selo "FSC", indicando utilizar insumos de fontes mistas, com papel produzido a partir de fontes responsáveis. As demais, que atuavam com resíduos metálicos, assumiam superficialmente o compromisso ambiental em suas missões.

\section{Contexto Regional Quanto à Gestão de Resíduos Sólidos}

Verifica-se que grande parte das cidades do $A B C$ encontra-se em Áreas de Proteção aos Mananciais (APM). Das sete cidades da região, apenas São Caetano do Sul não possui território em mananciais. Ribeirão Pires e Rio Grande da Serra apresentam praticamente $100 \%$ de seus territórios em áreas de mananciais; São Bernardo do Campo e Santo André apresentam metade de seu território em mananciais e Mauá e Diadema possuem aproximadamente entre $5 \%$ e $15 \%$ do território composto por mananciais. Neste conjunto, a ausência de áreas para instalação de aterros sanitários torna-se um desafio potencial para a região (PRGIRS, 2016). Em geral, a destinação final ambientalmente adequada dos resíduos sólidos e rejeitos é uma barreira comum às gestões municipais. Dados da última Pesquisa Nacional de Saneamento Básico (PNSB), realizada em 2008 , constataram que $50,8 \%$ dos municípios brasileiros ainda recorriam a vazadouros a céu aberto, conhecidos como lixões, como destino principal de seus resíduos (IBGE, 2011).

A região do Grande $A B C$, mesmo com o esgotamento de áreas para aterros sanitários, contempla a Central de Tratamento de Resíduos - Lara, em Mauá, este o único aterro que atende a todos os municípios da região. Excetua-se apenas o caso do município de Santo André, que devido à ampliação de seu próprio aterro, deixou de destinar seus resíduos ao aterro da Lara, o qual não é público e cobra pelo serviço (GUARDABASSIO; PEREIRA, 2015). Ademais, a região possui outras fontes de apoio aos programas municipais de coleta seletiva. A infraestrutura conta com áreas receptoras e de tratamento, de forma a permitir e priorizar o correto beneficiamento e valoração dos resíduos, tais como: centrais de triagem, ecopontos e Áreas de Transbordo e Triagem (ATT). 
Os equipamentos públicos devem comportar as 2.506 t/dia de Resíduos Sólidos Urbanos (RSU) produzidos na região (CETESB, 2016). Tais dados foram extraídos pela média encontrada na relação entre o Inventário Estadual de Resíduos Sólidos, estudados no período de 2011 a 2016 pela Companhia Ambiental do Estado de São Paulo (Cetesb) e pelas informações do CIGABC, o qual utilizou fontes do IBGE e prefeituras do Grande $A B C$ no período de 2015. Diante deste cenário, é necessário traçar estratégias diferenciadas para o gerenciamento dos resíduos sólidos, integrando-as regionalmente.

No caso do $A B C$ Paulista, o equacionamento quanto à destinação final dos resíduos sólidos, em vista das ações conjuntas, apresenta-se como um assunto latente aos gestores da região desde meados da década de 90 . A região é percursora na criação de um consórcio intermunicipal. Tal iniciativa foi constituída no início dos anos 90 como uma associação civil de direito privado para atuar como órgão articulador de políticas públicas setoriais, entre elas as relacionadas à destinação dos resíduos sólidos. A princípio, definiu-se que o consórcio trataria de diversos assuntos, desde a gestão ambiental, o gerenciamento e destino de resíduos sólidos até o desenvolvimento econômico local (KLINK, 2009). A gestão dos Resíduos Sólidos Urbanos foi um dos alicerces da constituição do agora denominado Consórcio Intermunicipal Grande ABC (PRGIRS, 2016).

Diante do incentivo da PNRS para que os municípios integrantes de arranjos regionalizados elaborassem a gestão integrada dos resíduos sólidos (BRASIL, 2016), surgem os primeiros estudos do futuro Plano Regional de Gestão Integrada de Resíduos Sólidos (PRGIRS) do Grande ABC. O PRGIRS do Grande ABC foi divulgado no final de 2016. O documento destaca-se pelos desafios propostos quanto à gestão e manejo de resíduos sólidos na região e as consequentes propostas, além do estabelecimento de princípios, diretrizes e metas para atendimento da ordem de prioridades estabelecida pela Lei $\mathrm{n}$ 12.305/2010. O PRGIRS estabelece as metas regionais quanto aos sistemas de retorno e recuperação dos resíduos sólidos e tal planejamento deve ser condizente com a realidade de cada município. Para tanto, dirigindo-se aos objetivos deste estudo, serão analisados a partir da próxima seção a base dessas metas, ou seja, os sistemas de retorno e logística reversa propostos nos Planos Municipais de Gestão Integrada de Resíduos Sólidos.

\section{Análise dos Planos Municipais de Gestão Integrada de Resíduos Sólidos}

Realizou-se uma pesquisa documental a fim de obter dos Planos Municipais de Gestão Integrada de Resíduos Sólidos existentes nas cidades da Região do ABC Paulista os levantamentos das metas de redução e das formas propostas para destinação final ambientalmente adequada dos resíduos e rejeitos. A pesquisa foi executada por meio de informações dos sites institucionais das prefeituras, acervo de órgãos/subsidiárias ambientais e artigos acadêmicos. A partir do artigo 19 da Lei no 12.305/2010, foram selecionados os incisos de conteúdo mínimo exigido para os Planos Municipais de Gestão Integrada de Resíduos Sólidos em conformidade com um dos objetivos deste estudo. 
Quadro 1 - Categorização dos itens para análise do conteúdo dos Planos Municipais

\begin{tabular}{|c|c|}
\hline & lise \\
\hline $\begin{array}{l}\text { a) Metas de redu- } \\
\text { ção }\end{array}$ & 1.a - Metas para redução da quantidade de rejeitos; \\
\hline \multirow{5}{*}{$\begin{array}{l}\text { b) Formas pro- } \\
\text { postas para } \\
\text { destinação final } \\
\text { ambientalmente } \\
\text { adequada dos re- } \\
\text { síduos e rejeitos }\end{array}$} & $\begin{array}{l}\text { 2.b - Identificação dos resíduos sólidos e dos geradores sujeitos ao plano } \\
\text { de gerenciamento específico; }\end{array}$ \\
\hline & 3.b - Valorização dos resíduos sólidos; \\
\hline & $\begin{array}{l}\text { 4.b - Forma de cobrança dos custos da prestação dos serviços públicos de } \\
\text { manejo de resíduos sólidos; }\end{array}$ \\
\hline & $\begin{array}{l}\text { 5.b - Formas e dos limites da participação do poder público local na cole- } \\
\text { ta seletiva e na logística reversa; }\end{array}$ \\
\hline & $\begin{array}{l}\text { 6.b - Controle e a fiscalização dos planos de gerenciamento de resíduos } \\
\text { sólidos. }\end{array}$ \\
\hline
\end{tabular}

Fonte: Dados da Pesquisa, 2017.

Cada plano possui suas especificidades, e devido a isto, analisou-se localmente cada documento (Quadro 2). Excetuou-se deste exame o município de Rio Grande da Serra por não ter desenvolvido o Plano Municipal de Gestão Integrada de Resíduos Sólidos. Também foram suprimidas, mas não excluídas, análises quanto às ações públicas para resíduos especiais, como os Resíduos da Construção Civil (RCC). Nestes casos, há legislações específicas que regulam o setor e seus eventuais prejuízos ao meio ambiente, fugindo do escopo da PNRS.

Quadro 2 - Sintetização dos itens para análise do conteúdo dos Planos Municipais

\begin{tabular}{|c|c|c|c|c|c|c|}
\hline \multirow[b]{2}{*}{ Itens de análise } & \multicolumn{6}{|c|}{ Municípios } \\
\hline & $\begin{array}{l}\text { Santo } \\
\text { André }\end{array}$ & São Bernardo & São Caetano & Diadema & Mauá & $\begin{array}{c}\text { Ribeirão } \\
\text { Pires }\end{array}$ \\
\hline $\begin{array}{l}\text { 1.a - Metas para redução } \\
\text { da quantidade de } \\
\text { rejeitos; }\end{array}$ & $\begin{array}{l}\text { Programas } \\
\text { de gestão e } \\
\text { coleta } \\
\text { seletiva }\end{array}$ & $\begin{array}{c}\text { Programas } \\
\text { diversos }\end{array}$ & $\begin{array}{l}\text { Conforme } \\
\text { Plano } \\
\text { Nacional }\end{array}$ & $\begin{array}{l}\text { Sim (separa } \\
\text { domiciliares e } \\
\text { outros } \\
\text { geradores) }\end{array}$ & $\begin{array}{l}\text { Sim (com } \\
\text { diretrizes e } \\
\text { metas) }\end{array}$ & $\begin{array}{l}\text { Sim (coleta } \\
\text { seletiva) }\end{array}$ \\
\hline $\begin{array}{l}\text { 2.b - Identificação dos } \\
\text { resíduos sólidos e dos } \\
\text { geradores sujeitos ao } \\
\text { plano de gerenciamento } \\
\text { específico; }\end{array}$ & $\begin{array}{l}\text { Cadastro no } \\
\text { SEMASA }\end{array}$ & $\begin{array}{l}\text { Conforme art. } \\
20 \text { e } 21 \text { da } \\
\text { PNRS }\end{array}$ & $\begin{array}{l}\text { Sim (Agentes } \\
\text { Públicos e } \\
\text { Privados) }\end{array}$ & $\begin{array}{l}\text { Não estabelece a } \\
\text { identificação } \\
\text { dos geradores da } \\
\text { iniciativa } \\
\text { privada }\end{array}$ & $\begin{array}{l}\text { Resíduos da } \\
\text { saúde e da } \\
\text { indústria }\end{array}$ & $\begin{array}{l}\text { Resíduos da } \\
\text { saúde }\end{array}$ \\
\hline $\begin{array}{l}\text { 3.b - Valorização dos } \\
\text { resíduos sólidos; }\end{array}$ & Cooperativas & $\begin{array}{l}\text { Cooperativas e } \\
\text { Recuperação } \\
\text { de Energia }\end{array}$ & $\begin{array}{l}\text { Inclusão de } \\
\text { catadores } \\
\text { domiciliados } \\
\text { no munícipio }\end{array}$ & Cooperativas & $\begin{array}{l}\text { Cooperativas / } \\
\text { Usina de } \\
\text { Biodiesel }\end{array}$ & Cooperativa \\
\hline $\begin{array}{l}\text { 4.b - Forma de cobrança } \\
\text { dos custos da prestação } \\
\text { dos serviços públicos de } \\
\text { manejo de resíduos } \\
\text { sólidos; }\end{array}$ & $\begin{array}{l}\text { Grandes } \\
\text { Geradores }\end{array}$ & $\begin{array}{l}\text { Grandes } \\
\text { Geradores }\end{array}$ & $\begin{array}{l}\text { Grandes } \\
\text { Geradores }\end{array}$ & $\begin{array}{l}\text { Resíduos da } \\
\text { saúde e os } \\
\text { provenientes da } \\
\text { construção civil }\end{array}$ & Não é taxativo & $\begin{array}{c}\text { Resíduos da } \\
\text { saúde e da } \\
\text { indústria }\end{array}$ \\
\hline $\begin{array}{l}\text { 5.b - Formas e dos } \\
\text { limites da participação } \\
\text { do poder público local } \\
\text { na coleta seletiva e na } \\
\text { logística reversa; }\end{array}$ & Sim & $\begin{array}{l}\text { Resíduos de } \\
\text { Saúde }\end{array}$ & $\begin{array}{l}\text { Industrial, } \\
\text { serviços de } \\
\text { saúde e } \\
\text { grandes } \\
\text { geradores }\end{array}$ & $\begin{array}{l}\text { Resíduos da } \\
\text { saúde e os } \\
\text { provenientes da } \\
\text { construção civil }\end{array}$ & $\begin{array}{l}\text { Resíduos da } \\
\text { saúde e da } \\
\text { indústria }\end{array}$ & $\begin{array}{c}\text { Resíduos da } \\
\text { saúde e da } \\
\text { indústria }\end{array}$ \\
\hline $\begin{array}{l}\text { 6.b - Controle e a } \\
\text { fiscalização dos planos } \\
\text { de gerenciamento de } \\
\text { resíduos sólidos. }\end{array}$ & $\begin{array}{l}\text { Cita multas, } \\
\text { mas não } \\
\text { determina o } \\
\text { resíduo }\end{array}$ & Não é taxativo & $\begin{array}{l}\text { Serviços de } \\
\text { saúde }\end{array}$ & $\begin{array}{l}\text { Agência de } \\
\text { Regulação e } \\
\text { Fiscalização }\end{array}$ & $\begin{array}{l}\text { Resíduos da } \\
\text { saúde e da } \\
\text { indústria }\end{array}$ & $\begin{array}{l}\text { Resíduos } \\
\text { industriais }\end{array}$ \\
\hline
\end{tabular}

Fonte: Dados da Pesquisa, 2017. 


\section{Percepções dos Administradores de MPE da Região do ABC Paulista}

Tendo como histórico os Planos Municipais, apresentam-se as análises e as discussões quanto às percepções dos administradores de MPEs recebidas pelo questionário autoaplicado e/ou entrevistas realizadas durante os meses de setembro e novembro de 2017. Tais instrumentos de coleta foram preenchidos por 29 respondentes. O roteiro das entrevistas foi guiado pelos próprios questionários, o que proporcionou um aprofundamento das questões, especialmente das principais categorias/subcategorias de MPEs dos três segmentos da economia presentes na região. Ademais, paralelamente houve uma pesquisa no site institucional das empresas na busca por dados relativos ao comprometimento ambiental. O anonimato quanto ao nome dos respondentes (e de seus respectivos negócios) foi uma condição necessária para que os entrevistados versassem espontaneamente sobre suas percepções. Tal condição trouxe liberdade a eles, uma vez que a exposição refletiria uma insegurança (conforme muitos citaram em um primeiro contato). Ademais, houve uma preocupação na análise quanto ao vínculo destes com a MPE, diferenciando-os em "proprietários" e "gestores não proprietários", a fim de verificar a percepção de cada grupo, se necessário.

\section{Percepções Sobre Legislações e Normas Ambientais}

As questões da "Parte $A$ " investigaram o conhecimento dos respondentes sobre a gestão e o gerenciamento de resíduos sólidos relativos às legislações e normas, logística reversa e a inter-relação com o poder público local. Pouco mais da metade dos respondentes (55\%) afirmou não ter conhecimento sobre a Lei no $12.305 / 2010$, contudo uma parcela significativa (45\%) conhecia o texto federal que trata dos resíduos sólidos. Dentro da parcela que não conhecia a lei, o setor de serviços concentrou a maior quantidade de MPEs, seguido pelo comércio. O administrador SCS-03 afirmou: "Sei que existe uma lei sobre isso, mas pra falar a verdade nunca ouvi falar desta lei, nem sei se é federal, afinal vendemos todos os nossos resíduos, então nunca nos preocupamos". Por outro lado, dos administradores que afirmaram conhecer a lei, houve uma distribuição de $50 \%$ pelos setores de comércio e serviço, além de três indústrias. A empresa SA-09 afirmou: "Trabalho diretamente com esta questão, e preciso estar atento às leis ambientais". A Lei no 12.350/2010 não é específica ao setor empresarial e também não se mostra punitiva, ao contrário, é didática e abarca todos os atores da sociedade. Após quase oito anos de sua existência, dentro do universo das MPEs pesquisadas, percebe-se que a política ambiental ainda não penetrou integralmente nos processos das diversas atividades das Micro e Pequenas Empresas.

No mesmo campo, foi analisado se os administradores da amostra estudada conheciam o planejamento municipal quanto à gestão e ao gerenciamento dos resíduos locais. Acompanhando o item anterior, a parcela que não sabia da existência de um plano municipal para gestão dos resíduos sólidos foi de $69 \%$, compreendendo todos os três setores da economia. Por outro lado, Santo André, São Bernardo do Campo e São Caetano do Sul comportaram todas as MPEs que afirmaram conhecer o plano. Percebe-se, nesta amostra, que foram as cidades mais populosas e detentoras dos melhores índices do PIB na região que conseguiram popularizar suas políticas públicas quanto à gestão dos resíduos sólidos. Tais municípios possuem políticas públicas consolidadas na 
área de gestão de resíduos, principalmente quanto aos RSU, o que pode ter incitado os respondentes a reconhecerem a tratativa local. Observa-se que as MPEs dos demais municípios, mesmo produzindo resíduos da área de saúde e industriais, não conheciam o documento. Ademais, em pesquisa nos sites institucionais das MPEs respondentes, não houve menção quanto às legislações municipais, mesmo àquelas que afirmaram conhecê-las.

Quanto ao escopo da sustentabilidade empresarial, buscou-se ainda conhecer se as MPEs participantes dependiam de alguma autorização do poder público para o correto funcionamento de sua respectiva atividade empresarial. Na presente questão, um terço dos entrevistados admitiu não possuir conhecimento sobre o licenciamento ambiental, e dentro desta parcela, destaca-se a predominância dos setores de serviço e comércio ligados à estética, saúde e alimentação. Outros $55 \%$ declararam não necessitar de autorização para operarem, incluindo, expressivamente, o setor de comércio. Apenas uma MPE, voltada à manutenção de veículos automotores, declarou precisar realizar licenciamento ambiental convencional. As MPEs que trabalhavam com resíduos industriais declararam a necessidade de operar por licenciamento simplificado.

Buscando identificar se os administradores de MPEs seguem algum tipo de lei ambiental, 70\% dos respondentes afirmaram não obedecer. O administrador SCS-03 afirmou: "As normas ambientais são de responsabilidade da empresa que nos envia matéria-prima, aliás, não tem como fugir, mas de qualquer forma NUNCA fomos autuados". A empresa SA-06: "Não sei se sigo a lei, mas tento fazer certo porque estou preocupado com a minha saúde em primeiro lugar". Uma parcela de MPEs afirmou não conhecer os caminhos legais quanto ao cumprimento das normas ou de seu papel no contexto social relativo ao impacto ambiental de suas atividades. Segundo essa parcela, uma das causas era a burocracia e a falta de dinamismo, principalmente do poder público municipal, que os prejudicavam.

Detectou-se ainda que a grande massa de resíduos sólidos gerados pelas MPEs estudadas não passava por qualquer identificação e/ou classificação. A variação de setores pesquisados pode ter influenciado a parcela significativa de empresários (70\%) que não conhecem a NBR 10004:2004 e suas respectivas classes.

\section{Percepções Sobre a Necessidade de um Plano de Gerenciamento de Resíduos Sólidos}

Entre as MPEs da amostra que não conheciam a PNRS e os Planos Municipais, $66 \%$ declararam não ter conhecimento sobre a necessidade de realizar um Plano de Gerenciamento dos resíduos produzidos em seus negócios. Entre os que reconheciam a necessidade (28\%), e entendiam não possuir obrigação de apresentá-lo, estavam presentes principalmente MPEs do comércio e da indústria. Os respondentes da área de saúde formaram o grupo dos que reconheciam a necessidade de possuir um Plano de Gerenciamento de Resíduos Sólidos e, ainda, declararam que o procedimento era complexo.

No ambiente pesquisado, inferiu-se que o poder público estava mais próximo do grupo de profissionais da saúde. Tal percepção é reforçada na análise dos Planos Municipais selecionados neste estudo. Ademais, é preciso considerar a existência de outras normas que regulam o setor, como as da Vigilância Sanitária em suas diversas instân- 
cias, além do regimento profissional, editados pelos respectivos conselhos de classe. Por outro lado, os resíduos provenientes das atividades industriais, os quais também são constantemente vigiados pelas normas legais, seguindo as respostas dos empresários deste setor, não apresentam qualquer formalização junto ao poder público quanto as suas práticas de logística reversa.

\section{Percepções Sobre a Inter-Relação com o Poder Público Local: a disposição final dos rejeitos}

Entre os respondentes, $48 \%$ afirmaram não utilizar o serviço público de limpeza, enquanto $21 \%$ utilizava parcialmente tal processo. Tais percepções, somadas, refletem $69 \%$ da amostra. Exceto uma MPE que atuava dentro de um Shopping Center, com serviço contratado para limpeza (coleta dos resíduos e rejeitos), as demais configuravam-se nos diversos setores e cidades pesquisadas.

No grupo que afirma não utilizar o sistema público de limpeza, destacou-se a atividade de comércio varejista, contendo seis MPEs. Muitas vezes o varejo está inserido no fluxo de resíduos de pós-consumo (recebendo, por exemplo, caixas de papelão, embalagens, entre outros), e acabam repassando-os para os clientes, minimizando a quantidade de tais restos sob sua responsabilidade. As MPEs do setor de serviços afirmaram produzir trabalho intelectual sem produção de resíduos, apenas de rejeitos (como papéis e materiais de escritório), os quais são equiparados aos domésticos pelo poder público. Apenas uma empresa que produz resíduos de saúde afirmou não utilizar o serviço público de limpeza, mas por imposição da lei, uma vez que pratica o Plano de Gerenciamento.

Duas indústrias justificaram não utilizar o serviço público por uma questão econômica, pois seus resíduos possuem valor no mercado, revendendo-os para empresas contratadas. O proprietário SCS-03 declara: "Não sobra nada, o cavaco e restos de cortes de metais vão para latões. Depois de algum tempo, peso estas peças e quando elas atingem um peso " $x$ ", chamo uma empresa de sucata para comprar". Da mesma forma, o empresário SA-06 diz: "Junto tudo num canto, de vez em quando pego o carro e levo no sucateiro, mas não jogo nada para o Semasa".

São Bernardo do Campo, Diadema e Ribeirão Pires foram caracterizados por parte dos respondentes (14\%) por conter serviço inadequado de limpeza pública. Apresentam-se neste grupo MPEs dos três setores. O proprietário SBC-04 cita que o poder público local não se preocupava em realizar a coleta seletiva porta a porta, desestimulando a separação dos resíduos (úmidos e secos): "Praticamente tudo que jogo fora é reciclável, mas a prefeitura não faz questão nenhuma de coletar, aí tenho que recorrer pros pontos de coleta e nem sempre tenho tempo".

Tratando-se da efetividade dos Planos Municipais, especialmente quanto à sua interação no cotidiano das MPEs, abordou-se a gestão dos volumes de resíduos/rejeitos produzidos. Cerca de $55 \%$ das MPEs afirmaram não ter conhecimento sobre o volume máximo que pode ser utilizado no sistema público de limpeza, observando-se que nesta parcela havia proprietários e não proprietários. Dos seis Planos Municipais existentes na Região do $A B C$, cinco propõem ações sobre os considerados "grandes geradores" ou ao tratamento diferenciado pelo volume de resíduo/rejeito a ser administrado. 
Apesar de os Planos Municipais serem norteadores (e não restritivos), há regras municipais específicas para alguns tipos de resíduos, tais como os da saúde e da construção civil, além dos geradores de grandes volumes de massa orgânica (como feiras limpas, supermercados e demais setores da alimentação). Pelos dados apresentados quanto às MPEs que não conheciam os limites para despejo de seus resíduos para disposição final, infere-se que ou o poder local não consegue dar uma tratativa especial ao setor empresarial, abarcando-os nas políticas de saneamento geral, equiparando-os aos resíduos domésticos, ou as MPEs não se preocupam em dar a disposição correta de seus resíduos, sendo necessário observar as regras locais.

\section{Percepções Sobre o Gerenciamento de Resíduos Sólidos nas MPEs}

O segundo bloco do questionário (Parte B) registrou a percepção dos respondentes quanto à responsabilidade compartilhada na gestão e gerenciamento de resíduos sólidos; especificamente abordou as ações das MPEs no trato de seus resíduos produzidos. Os dados foram obtidos por uma escala do tipo Likert, sendo tratados estatisticamente no software SPSS Statitics ${ }^{\circ}$ e transportados para o Microsoft Excel ${ }^{\circ}$ para edição das frequências (f). Pelos dados obtidos no cálculo da moda pôde-se segmentar a análise em duas vertentes: (i) proposições que tendem a 'nunca' ser realizadas pelas MPEs e (ii) proposições que tendem a ser 'sempre' realizadas pelas MPEs. Desta forma, o quadro a seguir traz as principais percepções, e consequentes graus de concordância, dos empresários e gestores não proprietários de MPEs.

Quadro 3 - Resultado do grau de concordância das MPEs (Estatística Descritiva)

\begin{tabular}{|c|c|c|c|c|c|c|c|c|c|c|c|c|c|c|}
\hline \multirow[b]{2}{*}{ Item } & \multicolumn{2}{|c|}{ Nunca } & \multicolumn{2}{|c|}{ Poucas vezes } & \multicolumn{2}{|c|}{ Algumas vezes } & \multicolumn{2}{|c|}{ Muitas vezes } & \multicolumn{2}{|c|}{ Sempre } & \multirow[b]{2}{*}{ Mediana } & \multirow[b]{2}{*}{ Moda } & \multirow[b]{2}{*}{$\Sigma f(a b s)$} & \multirow[b]{2}{*}{$\Sigma f(\%)$} \\
\hline & $f(a b s)$ & $f(\%)$ & $f(a b s)$ & $f(\%)$ & $f(a b s)$ & $f(\%)$ & $f(a b s)$ & $f(\%)$ & $f(a b s)$ & $f(\%)$ & & & & \\
\hline Q01 & 21 & $72,40 \%$ & 2 & $6,9 \%$ & 2 & $6,9 \%$ & 1 & $3,4 \%$ & 3 & $10,3 \%$ & 1,0 & 1 & 29 & $100 \%$ \\
\hline Q02 & 11 & $37,9 \%$ & 9 & $31,0 \%$ & 7 & $24,1 \%$ & 1 & $3,4 \%$ & 1 & $3,4 \%$ & 2,0 & 1 & 29 & $100 \%$ \\
\hline Q03 & 6 & $20,7 \%$ & 5 & $17,2 \%$ & 2 & $6,9 \%$ & 2 & $6,9 \%$ & 14 & $48,3 \%$ & 4,0 & 5 & 29 & $100 \%$ \\
\hline Q04 & 21 & $72,4 \%$ & 1 & $3,4 \%$ & 2 & $6,9 \%$ & 2 & $6,9 \%$ & 3 & $10,3 \%$ & 1,0 & 1 & 29 & $100 \%$ \\
\hline Q05 & 10 & $34,5 \%$ & 3 & $10,3 \%$ & 5 & $17,2 \%$ & 0 & $0,0 \%$ & 11 & $37,9 \%$ & 3,0 & 5 & 29 & $100 \%$ \\
\hline Q06 & 10 & $34,5 \%$ & 3 & $10,3 \%$ & 3 & $10,3 \%$ & 0 & $0,0 \%$ & 13 & $44,8 \%$ & 3,0 & 5 & 29 & $100 \%$ \\
\hline Q07 & 14 & $48,3 \%$ & 4 & $13,8 \%$ & 3 & $10,3 \%$ & 1 & $3,4 \%$ & 7 & $24,1 \%$ & 2,0 & 1 & 29 & $100 \%$ \\
\hline Q08 & 20 & $69,0 \%$ & 2 & $6,9 \%$ & 4 & $13,8 \%$ & 1 & $3,4 \%$ & 2 & $6,9 \%$ & 1,0 & 1 & 29 & $100 \%$ \\
\hline Q09 & 5 & $17,2 \%$ & 7 & $24,1 \%$ & 3 & $10,3 \%$ & 3 & $10,3 \%$ & 11 & $37,9 \%$ & 3,0 & 5 & 29 & $100 \%$ \\
\hline Q10 & 13 & $44,8 \%$ & 6 & $20,7 \%$ & 4 & $13,8 \%$ & 0 & $0,0 \%$ & 6 & $20,7 \%$ & 2,0 & 1 & 29 & $100 \%$ \\
\hline Q11 & 8 & $27,6 \%$ & 8 & $27,6 \%$ & 0 & $0,0 \%$ & 2 & $6,9 \%$ & 11 & $37,9 \%$ & 2,0 & 5 & 29 & $100 \%$ \\
\hline Q12 & 7 & $24,1 \%$ & 2 & $6,9 \%$ & 7 & $24,1 \%$ & 0 & $0,0 \%$ & 13 & $44,8 \%$ & 3,0 & 5 & 29 & $100 \%$ \\
\hline Q13 & 14 & $48,3 \%$ & 1 & $3,4 \%$ & 1 & $3,4 \%$ & 3 & $10,3 \%$ & 10 & $34,5 \%$ & 2,0 & 1 & 29 & $100 \%$ \\
\hline Q14 & 5 & $17,2 \%$ & 1 & $3,4 \%$ & 3 & $10,3 \%$ & 3 & $10,3 \%$ & 17 & $58,6 \%$ & 5,0 & 5 & 29 & $100 \%$ \\
\hline
\end{tabular}

Fonte: Dados da Pesquisa, 2017.

Notas: (1) $f(a b s)$ : Frequência absoluta

(2) $f(\%)$ : Frequência relativa 


\section{Percepções das MPEs: contexto setorial, relação com o poder público e infraestrutura em prol do tratamento dos resíduos sólidos}

O bloco de questões abertas (Parte $\mathrm{C}$ ) trata das percepções dos administradores de MPEs quanto à responsabilidade compartilhada na gestão e no gerenciamento de resíduos sólidos. Observa-se, no teor dessa investigação: (i) o intuito em envolver os diversos atores que se inter-relacionam, como os concorrentes destas empresas e o poder público; (ii) a infraestrutura alocada em seu respectivo munícipio a fim de efetivar as ações de gerenciamento dos resíduos. As afirmativas mostraram que a maior parte dos proprietários de MPEs não concordou que seus concorrentes praticavam o gerenciamento de resíduos sólidos. Surgiram alguns rótulos indicando a "falta de comprometimento" e a necessidade de maior "rigidez quanto à fiscalização do poder público".

Por outro lado, os respondentes citaram algumas práticas que estão em consonância com metas do artigo 9o da PNRS - as ordens de prioridade na gestão e no gerenciamento de resíduos sólidos. Surgiram os rótulos "reciclagem" e "redução ou não geração". O reconhecimento do resíduo sólido como um bem econômico e de valor social (artigo 60 da Lei № 12.305/2010) foi mencionado na análise de um empresário de Diadema, o qual ainda creditou a mesma prática ao seu setor: "O meu comércio só gera caixas de papelão e sempre damos para os catadores venderem. Acho que outros fazem o mesmo". Outros empresários afirmaram agir de forma correta quanto à gestão dos resíduos, ao contrário de seus concorrentes. Ademais, os geradores de resíduos industriais entrevistados unanimemente reconheceram que seus concorrentes não praticavam tais medidas de gerenciamento.

Quanto à captação das opiniões dos gestores não proprietários, não houve detaIhamentos quanto ao setor em que atuam. Percebe-se, contudo, um respondente de São Bernardo do Campo que opera dentro de um Shopping Center, no qual o serviço de gerenciamento de resíduos é praticado por empresa contratada para tal fim. Neste caso, o empreendimento investe em conceitos ambientais presentes na PNRS, tais como a educação ambiental, separação dos resíduos e reciclagem.

A percepção dos empresários quanto à interação do poder público local mostrou-se negativa. Exceto por uma empresária de Santo André, da área de tecnologia, as demais MPEs declararam não haver interação com o poder público no trato da geração de resíduos sólidos oriundos de seus negócios. Captou-se rótulos como "não há preocupação", "negligência" e "falta de comunicação". Outra empresária de Santo André, que lida com resíduos da construção civil em obras nos diversos municípios do $A B C$ Paulista, afirmou: "Desconheço qualquer forma de reciclagem de resíduos da construção civil no ABC. Se preocupam apenas com os descartes das caçambas e têm ecopontos de descarte para a população em geral".

Ainda segundo um empresário da área industrial, o poder público faz-se presente na perspectiva do rigor legal, sobretudo quanto aos cumprimentos para manter o funcionamento de seu negócio, incluindo a gestão dos resíduos. Ao mesmo tempo, não há mecanismos claros para que as MPEs sigam corretamente as normativas. Em muitos casos, é necessário recorrer à ajuda de terceiros a fim de atender tais exigências. 
Os gestores não proprietários apresentaram diferentes percepções. Enquanto um gestor de Santo André afirmou não haver preocupação, outro de São Bernardo do Campo reconheceu que havia interação entre as indústrias e o poder público. Esta observação, no entanto, não se aplicava à sua MPE. Por outro lado, uma empresária de São Caetano do Sul, da área de estética, produtora de resíduos infectantes, afirmou que o poder público local executava uma atividade rotineira. Percebe-se - especificamente para este grupo - que a divisão de opiniões é decorrente da diferença de setores e atividades desenvolvidas. Além disso, estes profissionais estavam envolvidos exclusivamente em seus próprios processos e rotinas do negócio (e não propriamente no capital investido), entendendo de formas diferentes tais experiências e relações com o poder público.

Por fim, as MPEs trouxeram suas percepções quanto ao contexto da infraestrutura disposta em sua localidade no trato com os resíduos sólidos, tanto a pública quanto a oferecida pela iniciativa privada. As percepções das MPEs dividem-se entre os que acreditavam não haver infraestrutura suficiente, especialmente a pública; e os que avaliaram a estrutura como parcialmente ou plenamente adequada. Um empresário de Santo André, atuante na área de tratamento de água para reinserção no processo produtivo de lavanderias, traçou um panorama da situação: "Apenas acredito que há infraestrutura privada quando apresenta um plano para reduzir custos para as MPEs e há interesse em lucrar com isto - obviamente. Já a pública, além de não ajudar, atrapalha as empresas privadas a tratarem os resíduos em prol das MPEs" (Entrevistado SA-09. Dados da Pesquisa, 2017).

Para este perfil de empresário, o serviço público é ineficiente quanto à infraestrutura oferecida, mas ainda há fontes de negócios neste campo que podem ser exploradas. Por sua vez, um empresário de Diadema revelou que: "Adequado em partes, existe o sistema de bota fora que é eficiente, porém a política de reciclagem e orientação do que fazer com o lixo sólido é muito superficial. Por termos um baixo volume em lixo sólido e nossos materiais recicláveis são $100 \%$ destinados à reciclagem adequadamente, não temos problema na gestão de gerenciamento de resíduos sólidos" (Entrevistado DIA-07. Dados da Pesquisa, 2017). Outro empresário da mesma cidade apresentou sua visão de discordância com o sistema público: "Aqui só passa o caminhão de lixo, quando não está de greve".

Dois empresários de Ribeirão Pires retrataram a infraestrutura local: "Tratamento de resíduos? Não vejo isso em minha cidade"; "Não existe plano, muito menos infraestrutura". Nota-se que as percepções das MPEs de Diadema e Ribeirão Pires enfatizaram o distanciamento de projetos na área de gestão de resíduos. Por outro lado, um empresário de São Bernardo do Campo afirmou haver infraestrutura privada eficiente em sua cidade, ao contrário do serviço do poder público: "Apenas as privadas, elas vêm coletar na minha loja sem problema algum (plástico, papel, tecidos, etc.), já a pública não tem nada, nem coleta seletiva". Já em São Caetano do Sul, o empresário SCS-03 avaliou a situação de sua MPE segundo suas experiências profissionais: "O município, por exemplo, dispõe de locais para descarte de resíduos específicos. Quanto à estrutura privada, nossa coleta é privada. A decisão por utilizar a iniciativa privada é utilizada desde a época do meu avô".

Ademais, quatro das seis cidades pesquisadas possuíam MPEs que não conheciam o assunto. A situação fez-se presente também para um dos gestores não proprietários. Tal grupo, de forma geral, compartilhava da opinião dos proprietários de MPEs, não percebendo, ou mesmo apontando necessidade de melhorias, quanto à infraestrutura existente para as MPEs na gestão e no gerenciamento de resíduos. 


\section{CONSIDERAÇÕES FINAIS}

Buscou-se evidenciar o conhecimento e a percepção dos micro e pequenos empresários da região do $A B C$ Paulista quanto à gestão dos resíduos sólidos provenientes de seus respectivos processos produtivos. O cenário da análise ainda foi composto pelos Planos Municipais de Resíduos Sólidos, um documento emitido pelo poder público local que visa, sob diretrizes e metas, criar programas e ações quanto às estratégias de manejo e alocação dos resíduos e rejeitos.

Percebeu-se o distanciamento das MPEs quanto ao planejamento integrado das ações dos municípios. Mesmo aquelas que reconheciam suas responsabilidades com o poder público municipal, não perceberam que a infraestrutura - eventualmente disponível - poderia colaborar internamente em suas ações de controle dos resíduos sólidos. Os municípios do ABC Paulista, por sua vez, com exceção de Rio Grande da Serra, editaram seus Planos Municipais (em média) há cinco anos, tempo adequado para ajustes e correções quanto à gestão integrada de resíduos sólidos.

Após análise destes documentos públicos, conclui-se que as propostas atendem ao solicitado na PNRS, e mesmo havendo diferenças entre os planos, o roteiro proposto na Lei no 12.305/2010 foi acolhido. A questão central apresentada pelos dados atingidos, por sua vez, revela que, de um lado, há a formalidade existente quanto à gestão pública, ou seja, este ente propõe metas para a gestão do manejo dos resíduos e ainda as realiza num planejamento de longo prazo (20 anos), enquanto por outro lado não há medidas para abarcar os diversos atores da sociedade, mantendo a passividade quanto aos aspectos legais, e não ações agregadoras.

Quanto ao conteúdo dos relatos dos administradores (proprietários e gestores não proprietários), evidenciou-se um abismo comunicacional entre estes agentes, uma vez que o poder público se utiliza da formalidade institucional, enquanto as MPEs colocam-se na posição de agentes passivos, ou mesmo de clientes da municipalidade. A PNRS apregoa justamente o contrário, ou seja, incentiva que a responsabilidade compartilhada seja realmente colocada em prática, para que cada etapa da produção do resíduo - até que vire um rejeito - tenha a participação efetiva da sociedade.

Ainda, dentro dos programas propostos nos Planos Municipais que visem à redução da quantidade de rejeitos, percebeu-se que tais ações, sobretudo quanto aos programas de coleta seletiva, não atendem efetivamente o setor empresarial. Neste ponto destaca-se que o princípio do poluidor-pagador é um paradigma para os micro e pequenos empresários. Segundo as percepções evidenciadas, com destaque para os setores de saúde e indústria, as MPEs não recebem positivamente que o poder público lhes repasse os custos do manejo para disposição final ambientalmente adequada de seus restos.

Da mesma forma que as MPEs se sentem negligenciadas pelo poder público, elas não reconhecem que seus lucros advêm de suas atividades empresariais, as quais necessariamente produzem resíduos. Repassar para a sociedade este ônus é um antigo padrão estabelecido e, agora, alterado com o advento da PNRS (no caso dos municípios, com a aplicação dos Planos Municipais de Gestão Integrada de Resíduos Sólidos) - especialmente quantos aos papéis desenvolvidos na responsabilidade compartilhada pelo ciclo de vida dos produtos pelos geradores e do poder público. 
Demonstrou-se igualmente que as MPEs não possuem conhecimentos básicos sobre as leis e normas que regem a gestão dos resíduos sólidos e demais compromissos ambientais. Ademais, quando explorados os entendimentos sobre a necessidade de emitir um Plano de Gerenciamento de Resíduos Sólidos (Logística Reversa) ou de um Licenciamento Ambiental quanto ao impacto local de suas respectivas atividades empresariais, poucos administradores tomaram conhecimento sobre a questão tratada. Por outro lado, uma parcela significativa de entrevistados mostrou-se disposta quanto às práticas sustentáveis, preocupando-se em utilizar insumos menos agressivos ao meio ambiente em seus processos produtivos e em separar seus resíduos corretamente. 0 estudo captou a disponibilidade e ações em curso quanto ao atendimento às ordens de prioridade presentes na Política Nacional de Resíduos Sólidos (artigo 9o).

Concluiu-se, portanto, que a depender da natureza das atividades da empresa (comercial, industrial e serviços), o resultado é diferenciado. Além disso, a interação das MPEs com o poder público local não registrou coesão, com destaque para o excesso de formalismo e distanciamento entre as propostas apresentadas pelas prefeituras do $A B C$ nos Planos Municipais e as práticas relatadas pelos administradores. Uma das limitações do estudo deu-se em relação à amostra. A região do $A B C$ Paulista possui um grande número de MPEs a serem exploradas, além de outras regiões no Estado de São Paulo que incluam municípios participantes de arranjos institucionais (como consórcios intermunicipais) e demais localidades.

Quanto ao instrumento de pesquisa utilizado, conforme demonstram Marconi e Lakatos (2010), há algumas desvantagens na aplicação de questionários, como: (i) a percentagem pequena de retorno; (ii) grande número de perguntas sem respostas; (iii) impossibilidade de ajudar o informante em questões mal compreendidas; (iv) na leitura de todas as perguntas, antes de respondê-las, poderá uma questão influenciar a outra; (v) o desconhecimento das circunstâncias em que foram preenchidos torna difícil o controle e a verificação; (vi) a devolução tardia prejudica o calendário ou sua utilização. Registra-se, todavia, que não houve tais apontamentos por parte dos respondentes. Ademais, cerca de $40 \%$ da amostra foi entrevistada, pautada no próprio questionário autoaplicado, diminuindo a incidência de dúvidas e ampliando o campo de pesquisa.

A indisponibilidade e insegurança de alguns administradores também se tornaram fatores limitantes. $O$ anonimato diminuiu tal incidência, visto que alguns empresários não queriam, em um primeiro contato, expor as possíveis dificuldades no trato com o poder público.

Concluindo, não foi intenção deste estudo esgotar o assunto quanto à responsabilidade compartilhada pelo ciclo de vida dos produtos pelos seus geradores, especialmente na fase da gestão dos resíduos sólidos oriundos de tais atividades econômicas, da qual - direta ou indiretamente - coparticipará o poder público local. Espera-se, contudo, que tal pesquisa contribua com futuras investigações a respeito do tema.

\section{REFERÊNCIAS}

ABDULRAHMAN, M. D.; GUNASEKARAN, A.; SUBRAMANIAN, N. Critical barriers in implementing reverse logistics in the Chinese manufacturing sectors. Production Economics, n. 147, p. 460-471, 2014.

ABRELPE. Panorama dos resíduos sólidos no Brasil 2015. Disponível em: http://www.abrelpe.org.br/Panorama/panorama2015.pdf. Acesso em: 3 mar. 2017. 
AGÊNCIA ABC. Por dentro do Grande ABC. 2016. Disponível em: http://www.agenciagabc.com.br/grandeabc0709br/grandeabc/index.php?id=14 . Acesso em: 9 nov. 2016.

ARAGÃO, M. A. de S. Direito dos resíduos. Coimbra: Almedina, 2003.

ARAÚJO, S. M. V. G. de; JURAS, I. da A. G. M. Comentários à lei dos resíduos sólidos: Lei no 12.305, de 2 de agosto de 2010 (e seu regulamento). São Paulo: Pillares, 2011.

BARBIERI, J. C. Educação ambiental e a gestão ambiental em cursos de Graduação em Administração: objetivos, desafios e propostas. Revista de Administração Pública, v. 38, n. 6, p. 919-946, 2004.

BARBOSA, A.; BENEDUZZI, B.; ZORZIN, G.; MENQUIQUE. J.; LOUREIRO, M. C. Logística reversa o reverso da logística. 2005. Disponível em: http://www.guialog.com.br/ARTIGO394.htm. Acesso em: 10 jun. 2017. BRASIL, A. M.; SANTOS, F. Equilíbrio ambiental e resíduos na sociedade moderna. 3.ed. São Paulo: FAARTE Editora, 2007.

BRASIL. Lei Complementar n. 123, de 14 de dezembro de 2006. 2006. Disponível em: http://www.planalto.gov.br/ccivil_03/leis/LCP/Lcp123.htm. Acesso em: 2 jan. 2017.

BRASIL. Lei no 12.305, de 2 de agosto de 2010. Institui a Política Nacional de Resíduos Sólidos; altera a Lei no 9.605, de 12 de fevereiro de 1998; e dá outras providências. Disponível em: http://www.planalto.gov. br/ccivil_03/_ato2007-2010/2010/lei/l12305.htm. Acesso em: 12 jan. 2017.

BRASIL. Ministério do Meio Ambiente. Política de resíduos sólidos apresenta resultados em 4 anos. 2014. Disponível em: http://www.mma.gov.br/informma/item/10272-pol\%C3\%ADtica-de-res\%C3\%ADduos-s\%C3\%B3lidos-apresenta-resultados-em-4-anos. Acesso em: 21 jun. 2017.

BRASIL. Resíduos sólidos: planos intermunicipais de gestão integrada de resíduos sólidos. 2016. Disponível em: http://www.mma.gov.br/informma/itemlist/category/64-residuos-solidos. Acesso em: 22 out. 2017.

BROLLO, M. J.; SILVA, M. M. Política e gestão ambiental em resíduos sólidos. Revisão e análise sobre a atual situação no Brasil. In: CONGRESSO BRASILEIRO DE ENGENHARIA SANITÁRIA E AMBIENTAL, 21., 2001, João Pessoa, PB. Anais eletrônicos [...]. João Pessoa, PB: Abes, 2001. Disponível em: http://www. bvsde.paho.org/bvsaidis/brasil21/vi-078.pdf. Acesso em: 13 jul. 2017.

CETESB. COMPANHIA AMBIENTAL DO ESTADO DE SÃO PAULO. Inventário estadual de resíduos sólidos urbanos. 2016. Disponível em: http://solo.cetesb.sp.gov.br/wp-content/uploads/sites/18/2013/12/inventario-residuossolidos-2016.pdf. Acesso em 8 nov. 2017.

CHAVES, G. de L. D.; BATALHA, M. O. Os consumidores valorizam a coleta de embalagens recicláveis? Um estudo de caso da logística reversa em uma rede de hipermercados. Gestão \& Produção, v. 13, n. 3, p. 423-434, 2006.

CORRÊA, A. P. M.; SILVA, M. E. A logística reversa sob a perspectiva produção-mercado-consumo: o caso o Boticário. Revista de Gestão Ambiental e Sustentabilidade - GeAS, v. 2, n. 1, p. 97-122, 2013.

CSCMP. Supply Chain Management Definitions and Glossary. Available from: http://cscmp.org/CSCMP/ Educate/SCM_Definitions_and_Glossary_of_Terms/CSCMP/Educate/SCM_Definitions_and_Glossary_of_ Terms.aspx?hkey=60879588-f65f-4ab5-8c4b-6878815ef921. Cited: 4 abr. 2017.

CUNHA, A. S.; SOARES, T. C. Aspectos relevantes do planejamento no crescimento das Micro e Pequenas empresas (MPE). Revista da Micro e Pequena Empresa, v. 4, n. 3, p. 15-39, 2010.

DAHER, C. E.; SILVA, E. P. de la S.; FONSECA, A. P. Logística reversa: oportunidade para redução de custos através do gerenciamento da cadeia integrada de valor. Brazilian Business Review, v. 3, n. 1, p. 58-73, 2006.

DEMAJOROVIC, J.; CAIRES, E. F.; GONÇALVES, L. N. da S. Integrando empresas e cooperativas de catadores em fluxos reversos de resíduos sólidos pós-consumo: o caso ViraLata. Cadernos EBAPE.BR, v. 12, n. 7, p. 513-532, 2014.

DEMAJOROVIC, J.; HUERTAS, M. K. Z.; BOUERES, J. A.; SILVA, A. G. da; SOTANO, A. S. Logística reversa: Como as empresas comunicam o descarte de baterias e celulares? Revista de Administração de Empresas, v. 52, n. 2, p. 165-178, 2011.

DEMAJOROVIC, J.; MIGLIANO, J. E. B. Política Nacional de Resíduos Sólidos e suas implicações na cadeia da logística reversa de microcomputadores no Brasil. Gestão \& Regionalidade, v. 29, n. 87, p. 64-80, 2013. DOWLATSHAHI, S. A Framework for Design of Reverse Logistics Systems: A Warehousing Perspective. Missouri: University of Missouri, 2000.

FARIAS, J. S.; TEIXEIRA, R. M. A pequena e micro empresa e o meio ambiente: a percepção dos empresários com relação aos impactos ambientais. Organizações \& Sociedade, v. 9, n. 23, p. 1-20, 2002.

FIGUEIRÓ, P. S.; NASCIMENTO, L. F.; TREVISAN, M.; BOSSLE, M. B. Logística Reversa de pós-consumo: explorando motivações e superando limitações. Revista Gestão Industrial, v. 10, n. 2, p. 375-392, 2014. 
GARDIN. J. A. C.; FIGUEIRÓ, P. S.; NASCIMENTO, L. F. Logística reversa de pneus inservíveis: discussões sobre três alternativas de reciclagem para este passivo ambiental. Revista Gestão e Planejamento, v. 11, n. 2, p. 232-249, 2010.

GIACOBO, F.; ESTRADA, R. J. S.; CERETTA, P. S. Logística reversa: a satisfação do cliente no pós-venda. Revista Eletrônica de Administração, v. 9, n. 5, p. 1-17, 2003.

GIOVANNINI, F.; KRUGLIANSKAS, I. Fatores críticos de sucesso para a criação de um processo inovador sustentável de reciclagem: um estudo de caso. RAC, v. 12, n. 4, p. 931-951, 2008.

GLIEM, J. A.; GLIEM, R. R. Calculating, Interpreting, and Reporting Cronbach's Alpha Reliability Coefficient for Likert-Type Scales. Midwest Research to Practice Conference in Adult, Continuing, and Community Education, 2003.

GONÇALVES, M. A.; TANAKA, A. K.; AMEDOMAR, A. de A. A destinação final dos resíduos sólidos urbanos: alternativas para a cidade de São Paulo através de casos de sucesso. Future Studies Research Journal: Trends and Strategies, v. 5, n. 1, p. 96-129, 2013.

GONÇALVES-DIAS, S.; TEODÓSIO, A. S. S. Estrutura da cadeia reversa: "caminhos" e "descaminhos" da embalagem PET. Produção, v. 16, n. 3, p. 429-441, 2006.

GONZÁLES-TORRE, P.; ÁLVAREZ, M.; SARKIS, J.; ADENSO-DÍAZ, B. Barriers to the Implementation of Environmentally Oriented Reverse Logistics: Evidence from the Automotive Industry Sector. British Journal of Management, v. 21, p. 889-904, 2010.

GUARDABASSIO, E. V.; PEREIRA, R. da S. Gestão pública de resíduos sólidos urbanos na região do Grande ABC. Gestão \& Regionalidade, v. 31, p. 127-143, 2015.

GUNGOR, A.; GUPTA, S. M. Issues in environmentally conscious manufacturing and product recovery: a survey. Computers \& Industrial Engineering, v. 36, p. 811-853, 1998.

HORA, H. R. M.; MONTEIRO, G. T. R.; ARICA, J. Confiabilidade em questionários para qualidade: um estudo com o coeficiente Alfa de Cronbach. Produto \& Produção, v. 11, n. 2, p. 85-103, 2010.

IBGE. INSTITUTO BRASILEIRO DE GEOGRAFIA E ESTATÍSTICA. Atlas de saneamento 2011: Manejo de Resíduos Sólidos. 2011. Disponível em: https://biblioteca.ibge.gov.br/visualizacao/livros/liv53096_cap9.pdf. Acesso em: 12 out. 2017.

JESUS, F. S. M de; BARBIERI, J. C. Atuação das cooperativas de catadores de materiais recicláveis na logística reversa empresarial por meio de comercialização direta. Revista da Gestão Social e Ambiental, v. 7, n. 3, p. 20-36, 2013.

KLINK, J. Regionalismo e reestruturação urbana: uma perspectiva brasileira de governança metropolitana. Educação, Porto Alegre, v. 32, n. 2, p. 217-226, 2009.

LACERDA, L. Logística reversa: uma visão sobre os conceitos básicos e as práticas operacionais. Rio de Janeiro: COPPEAD; UFRJ, 2002.

LAVEZ, N.; SOUZA, V. M.; LEITE, P. R. O papel da logística reversa no reaproveitamento do "lixo eletrônico" - um estudo no setor de computadores. Revista de Gestão Social e Ambiental, v. 5, n. 1, p. 15-32, 2011.

LEITE, P. R. Logística reversa: meio ambiente e competitividade. 2. ed. São Paulo: Pearson Prentice Hall, 2009.

LEMOS, P. F. I. Resíduos sólidos e responsabilidade civil pós-consumo. 3. ed. São Paulo: Revista dos Tribunais, 2014.

LIMA, V. P. Política Nacional de Resíduos Sólidos: uma mudança de paradigma. Síntese. 2011. Disponível em: http://www.sintese.com/doutrina_integra.asp?id=1171. Acesso em: 12 dez. 2016.

LIPOVETSKY, Gilles. A felicidade paradoxal: ensaio sobre a sociedade de hiperconsumo. Trad. Maria Lúcia Machado. São Paulo: Companhia das Letras, 2007.

MAIA, H. J. L.; ALENCAR, L. D. de; BARBOSA, E. M.; BARBOSA, M. de F. N. Política Nacional de Resíduos Sólidos: um marco na legislação brasileira. Polêm!CA, v. 13, n. 1, 2014.

MALINVERNI, C. Tomra Latasa: a logística da reciclagem. Revista Tecnologística, edição 80, p. 28-34, 2002. MARCONI, M. A.; LAKATOS, E. M. Fundamentos de metodologia científica. São Paulo: Atlas, 2010.

MONTOYA, C. C. P.; GOMEZ, J. C. O.; HOLGUIN, C. J. V.; LOZADA, P. T.; REBELLON, L. F. M. Reverse Logistics in the plastics subsector: Main facilitors and barriers. Ingeniería e Investigación, v. 35, n. 3, p. 27-33, 2015. NOVAES, A. G. Logística e gerenciamento de distribuição. 2. ed. Rio de Janeiro: Campus, 2004.

OLIVEIRA, L. da S. de; DEMAJOROVIC, J.; SOUZA, M. T. S. de; CAMPOS, J. B. S. de. Logística reversa no varejo: barreiras e motivações para retorno de produtos e suas embalagens. In: ENCONTRO INTERNACIONAL SOBRE GESTÃO EMPRESARIAL E MEIO AMBIENTE, 17., 2015, São Paulo. Anais eletrônicos [...]. São Paulo, SP: USP, 2015. Disponível em: http://engemausp.submissao.com.br/17/anais/arquivos/100.pdf. Acesso em: 13 abr. 2017. 
PEREIRA, T. C. G. Política Nacional de Resíduos Sólidos: nova regulamentação para um velho problema. Direito e Justiça, v. 11. n. 17, 2011.

POZO, H.; AKABANE, G; K; SILVA, P. A M. da. As barreiras que as Micro e Pequenas Empresas da Região de Bauru/SP enfrentam para implantar um programa de Logística Reversa. In: ENCONTRO INTERNACIONAL SOBRE GESTÃO EMPRESARIAL E MEIO AMBIENTE, 16., 2014, São Paulo. Anais eletrônicos [...]. São Paulo, SP: USP, 2014. Disponível em: http://www.engema.org.br/XVIENGEMA/208.pdf. Acesso em: 15 mar. 2016.

PRGIRS. PLANO REGIONAL DE GESTÃO INTEGRADA DE RESÍDUOS SÓLIDOS. Consórcio Intermunicipal Grande ABC. 2016. Disponível em: http://consorcioabc.sp.gov.br/imagens/noticia/Plano\%20Regional\%20 de\%20Gestao\%20Integrada\%20de\%20Residuos\%20Solidos\%20do\%20Grande\%20ABC_completo\%20 para\%20site.pdf. Acesso em: 30 set. 2017.

RALIO, V. R. Z.; DONADONE, J. C. Estudo sobre o histórico de atuação do Sebrae na consultoria para micro e pequenas empresas brasileiras. Gestão da Produção, Operações e Sistemas, v. 2, p. 33-47, 2015.

RAUBER, M. E. Apontamentos sobre a Política Nacional de Resíduos Sólidos, instituída pela Lei Federal 12.305, de 2/8/2010. Revista Eletrônica Gestão, Educação e Tecnologia Ambiental, v. 4, p. 1-24, 2011.

ROGERS, D. S.; TIBBEN-LEMBKE, R. S. Going Backwards: Reverse Logistics Trends and Practices. Nevada: University of Nevada, 1998.

RUBIO, S.; CHAMORRO, A.; MIRANDA, F. J. Characteristics of the research on reverse logistics (1995-2005). International Journal of Production Research, v. 46, n. 4, p. 1.099-1.120, 2008.

SEADE. FUNDAÇÃO SISTEMA ESTADUAL DE ANÁLISE DE DADOS. Abrangência das regiões administrativas. 2010. Disponível em: http://www.seade.gov.br/lista-produtos/?abrangencia=regioes-administrativas. Acesso em: 29 out. 2016.

SEBRAE. SERVIÇO BRASILEIRO DE APOIO ÀS MICRO E PEQUENAS EMPRESAS. Anuário do trabalho na Micro e Pequena Empresa 2014. 7. ed. São Paulo: Dieese, 2015.

SHIBAO, F. Y.; MOORI, R. G.; SANTOS, M. R. dos. A logística reversa e a sustentabilidade empresarial. In: SEMINÁRIOS EM ADMINISTRAÇÃO, 13., 2010, São Paulo. Anais eletrônicos [...]. São Paulo, SP: USP, 2010. Disponível em: http://web-resol.org/textos/a_logistica_reversa_e_a_sustentabilidade_empresarial.pdf. Acesso em: 12 dez. 2016.

SILVA, M. C. G. da; COLMENERO, J. C. A logística reversa como forma de desenvolvimento sustentável e competitivo das empresas. Publicatio UEPG, v. 16, n. 2, p. 97-104, 2010.

SILVA, M. S. da; CRUZ, H. A. da. Logística reversa: análise no fluxo de cabides. In: SIMPÓSIO DE EXCELÊNCIA EM GESTÃO E TECNOLOGIA, 8., 2011, Resende, RJ. Anais eletrônicos [...]. Resende, RJ: UFSC, 2011. Disponível em: http://www.inf.aedb.br/seget/artigos11/40514596.pdf. Acesso em: 15 jul. 2017.

SILVA, A. A.; LEITE, P. R. Empresas brasileiras adotam políticas de logística reversa relacionadas com o motivo de retorno e os direcionadores estratégicos? Revista de Gestão Social e Ambiental, v. 6, n. 2, p. 79-92, 2012.

SINIR. SISTEMA NACIONAL DE INFORMAÇÕES SOBRE A GESTÃO DOS RESÍDUOS SÓLIDOS. Logística reversa. 2011. Disponível em: https://sinir.gov.br/web/guest/logistica-reversa. Acesso em: 3 fev. 2017.

TACHIZAWA, T.; DE ANDRADE, R. O. B. Gestão socioambiental: estratégias na nova era da sustentabilidade. 2. ed. São Paulo: Elsevier, 2008.

TACHIZAWA, T. Gestão ambiental e a responsabilidade social corporativa: estratégias de negócios focadas na realidade brasileira. 8. ed. São Paulo: Atlas, 2017.

TADEU, H. F. B. T.; SILVA, J. T. M.; PEREIRA, A. L.; CAMPOS; P. M. S.; BOECHAT, C. B. Logística reversa e sustentabilidade. São Paulo: Cengage Learning, 2012.

TOMAZ, C. A responsabilidade dos geradores e do poder público na política nacional de resíduos sólidos. 2012. Dissertação (Mestrado em Direitos Difusos e Coletivos) - Universidade Metropolitana de Santos, Santos, 2012.

VARGAS, S.; VIEIRA, G. B. B.; SILVA, R. M. As práticas de logística reversa em um grupo de empresas metalúrgicas localizado no Sul do Brasil. Revista Organizações em Contexto, v. 12, n. 24, p. 91-116, 2016.

VOSS, B. L.; PFITSCHER, E. D.; ROSA, F. S.; RIBEIRO, M. S. Evidenciação ambiental dos resíduos sólidos de companhias abertas no Brasil potencialmente poluidoras. Revista Contabilidade \& Finanças - USP, v. 24, n. 62, p. 125-141, 2013.

ZAMBRANO, T. F.; MARTINS, M. F. Utilização do método FMEA para avaliação do risco ambiental. Gestão \& Produção, v. 14, n. 2, p. 295-309, 2007.

ZUCATTO, L. C.; WELLE, I.; SILVA, T. N. da. Cadeia reversa do óleo de cozinha: coordenação, estrutura e aspectos relacionais. Revista de Administração de Empresas, v. 53, n. 5, p. 442-453, 2013. 